\title{
Management of disseminated intravascular coagulation associated with placental abruption and measures to improve outcomes
}

\author{
Jun Takeda, Satoru Takeda \\ Department of Obstetrics and Gynecology, Juntendo University Faculty of Medicine, Tokyo, Japan
}

Placental abruption is a condition that should be carefully considered in perinatal management because it is associated with serious events in both the mother and neonate, such as intrauterine fetal death, cerebral palsy, obstetric critical bleeding, and uncontrollable bleeding. The concomitant presence of disseminated intravascular coagulation (DIC) more easily causes critical bleeding that may necessitate hysterectomy or multi-organ failure resulting in maternal death. Therefore, early management should be provided to prevent progression to serious conditions by performing both hemostatic procedures and DIC treatment. To take measures to improve the outcomes in both the mother and neonate, health guidance for pregnant women, early diagnosis, early treatment, development of the emergency care system, and provision of a system for transport to higher-level medical institutions should be implemented.

Keywords: Cerebral palsy; Disseminated intravascular coagulation; Fibrinogen; Obstetric surgical procedures; Placental abruption

\section{Introduction}

Placental abruption, a premature separation of the normally implanted placenta from the uterus before fetal delivery, occurs in $0.4-1.0 \%$ of all pregnancies [1-7]. The occurrence of concomitant disseminated intravascular coagulation (DIC) can cause a range of problems to both the mother and neonate such as emergency cesarean delivery due to non-reassuring fetal status, cerebral palsy, critical bleeding, uncontrollable bleeding requiring hysterectomy, multi-organ failure, and maternal and fetal death [2,3,8-11]. Thus, placental abruption is a condition requiring an appropriate perinatal management. According to the analysis of the Japan Obstetric Compensation System for Cerebral Palsy [12,13], which targets cerebral palsy cases delivered after a periviable period, occurring mostly before and during the delivery, and covering $99.9 \%$ of childbirth fatalities [12], 793 cases were diagnosed with cerebral palsy. Among them, 431 cases had cerebral palsy attributable to a single cause, and placental abruption accounted for 145 cases, ranking as the most common cause. Therefore, placental abruption is known as one of the most important causative conditions for cerebral palsy [14]. Risk factors for placental abruption include hyper- tensive disorder of pregnancy, chorioamnionitis, advanced maternal age, smoking, cocaine use, and undernutrition [15].

The rate of recurrence in the subsequent pregnancy was reported as 5.8\% [16], and health guidance and preconceptional care are important. While early diagnosis and prompt treatment are both critical for improving the outcomes of both the mother and neonate, coordination with high-level medical facilities and enhancement of the emergency patient transport system are also important.

Patients with placental abruption may further increase

Received: 2018.12.21. Revised: 2019.03.26. Accetped: 2019.04.17. Corresponding author: Jun Takeda

Department of Obstetrics and Gynecology, Juntendo University Faculty of Medicine, 2-1-1 Hongo, Bunkyo-ku, Tokyo 113-8421, Japan

E-mail: jtakeda@juntendo.ac.jp

https://orcid.org/0000-0002-6195-8971

Articles published in Obstet Gynecol Sci are open-access, distributed under the terms of the Creative Commons Attribution Non-Commercial License (http://creativecommons. org/licenses/by-nc/3.0/) which permits unrestricted non-commercial use, distribution, and reproduction in any medium, provided the original work is properly cited.

Copyright $\odot 2019$ Korean Society of Obstetrics and Gynecology 


\title{
Obstetrics \& Gynecology Science
}

\author{
Vol. 62, No. 5, 2019
}

along with the increasing tendency to marry and become pregnant later in life [17]; thus, it cannot be avoided. Therefore, measures against its associated conditions should be established. In addition, hysterectomy to save the life of the mother in the event of bleeding due to DIC should be reconsidered from the viewpoint of fertility preservation. In this review, possible measures against DIC in patients with placental abruption, management methods that allow fertility preservation while preventing hysterectomy, and future measures to improve the outcomes of both the mother and neonate should be discussed.

\section{Management of disseminated intravascular coagulation}

\section{Characteristic features of bleeding and hemostatic strategies}

Bleeding associated with placental abruption is classified as the concealed or revealed abruption [18]. The former type is characterized by rapid separation of the placenta, often occurring in severe cases accompanied by fetal death or DIC at an early stage and resulting in poor outcomes for both the mother and neonate. The severity of the condition is classified according to Page's classification into mild, moderate, and severe, based on the size of the area of placental separation [19]. If concomitant DIC is present, uterine atony may occur after fetal delivery, facilitating further bleeding and creating a vicious cycle. If the fetus is alive, delivery should be initiated as expeditiously as possible, and attention should be focused on the treatment of DIC. If intrauterine fetal death occurs, whether to perform vaginal delivery or cesarean section should be determined based on the condition of the cervix and labor pain status. Implementation of excessively prolonged induction or augmentation of delivery by persisting too much importance to vaginal delivery should be avoided to prevent multi-organ failure. In any event, delivery should be managed under the circumstances that DIC treatment is fully available. In cases of DIC and atonic bleeding after the fetal delivery, appropriate primary hemostasis and blood transfusion to supplement coagulation factors are important, representing the keys to prevent hysterectomy.

\section{Transfusion therapy}

In cases with massive critical bleeding, accurate assessment of the blood loss volume may be difficult, and underestimation is common, which often causes delay in the initiation of blood transfusion. Therefore, an early response to such bleeding is necessary according to the Japanese Clinical Practice Guide for Critical Obstetrical Hemorrhage [20]. In facilities where stored blood is not available, the following available hemostatic measures should be performed until the blood is delivered: massive fluid therapy, infusion of albumin and intrauterine packing, bimanual compression of the uterus, and aortic compression, among others. For blood transfusion, packed red blood cell (RBC) and fresh frozen plasma (FFP) should be infused at a 1:1 ratio, the same as in trauma cases [21]. Transfusion of RBC alone cannot maintain the circulating blood volume, although it facilitates dilutional coagulopathy by enhancing the dilution of coagulation factors. In addition, hemolysis of transfused RBCs causes hyperkalemia, leading to arrhythmia and cardiac arrest. In cases of placental abruption, which causes consumption coagulopathy in the early stage, more FFP should be provided at an RBC-FFP ratio of greater than 1:1 [22].

The blood fibrinogen level is commonly less than 100 $150 \mathrm{mg} / \mathrm{dL}$ or even below the measurable limit in patients with consumption DIC due to placental abruption or amniotic fluid embolism and established DIC after massive bleeding $[23,24]$. The blood fibrinogen level can be measured with point-of-care monitoring earlier than normal examination at the central clinical laboratory and adjusted to $150 \mathrm{mg} / \mathrm{dL}$ or more by rapidly administering FFP, fibrinogen concentrate, or cryoprecipitate $[25,26]$. Gradual adjustment does not produce DIC resolution, because bleeding persists with consumption of coagulation factors during their slow replenishment, which may lead to negative balance of coagulation factors. In particular, in patients with placental abruption accompanied by intrauterine fetal death, the fibrinogen level is often under $100 \mathrm{mg} / \mathrm{dL}$, often requiring FFP to take priority over RBC $[22,25,26]$.

In general, transfusion of 15 units of FFP or $3 \mathrm{~g}$ of fibrinogen concentrate is necessary to increase the blood fibrinogen level by more than $100 \mathrm{mg} / \mathrm{dL}$ [27]. Elimination of the bleeding tendency requires rapid transfusion of 10 or more units of FFP, rather than RBC. In the absence of such transfusion, bleeding remains uncontrolled, with the bleeding tendency persisting unchanged for days. Obstetric DIC management targets elimination of DIC within 24 hours, by performing rapid infusion of FFP to obtain a blood fibrinogen level of 


\section{Obstetrics \& Gynecology Science}

Jun Takeda, et al. Management of DIC with abruption

$150 \mathrm{mg} / \mathrm{dL}$ or more $[28,29]$ and a prothrombin time (PT) activity percentage of $70 \%$ or more. During night hours when coagulation tests are not feasible in some facilities, a total protein level of $4.0 \mathrm{~g} / \mathrm{dL}$ should be the target.

The problem of rapid FFP infusion is asymptomatic $\left(\mathrm{SpO}_{2}\right.$ $95 \%$ or less) or symptomatic pulmonary edema occurring in many patients. Therefore, diuretics or carperitide should be administered early enough, with the use of a central venous pressure or $\mathrm{SpO}_{2}$ monitor. Administration of $3 \mathrm{~g}$ of fibrinogen concentrate is extremely useful for the treatment of DIC because it rapidly increases the blood fibrinogen level, allowing reduction of the FFP dose and thereby diminishing the circulatory load $[26,28]$. In patients with life-threatening critical bleeding, non-cross-matched type O RBC and type AB FFP should be used without hesitation according to the guideline [20]. If the platelet count is decreased to $20,000-50,000 / \mu \mathrm{L}$, resulting in a bleeding tendency, platelet transfusion is necessary. Administration of 10 units of platelet concentrate increases the blood platelet level by approximately 25,000$30,000 / \mu \mathrm{L}$. In patients suffering critical massive obstetric bleeding with a full-dose FFP that failed to stop the bleeding, administration of recombinant activated factor VII should also be considered [29].

\section{Hemostatic procedure}

Appropriate hemostatic procedures should be performed along with systemic management and appropriate infusion therapy. For hemostasis in patients suffering due to atonic bleeding during cesarean section and due to the surface of the separated placenta, bimanual compression of the uterus or uterotonic therapy as well as intrauterine gauze packing or balloon tamponade should be performed. When hemostasis is not achieved, compression suturing is also useful [30-33]. In patients with atonic bleeding from the uterine body, suture ligation of the ascending branch of the uterine artery with the muscular layer may achieve hemostasis; however, subsequent complications due to uterine blood flow obstruction are also reported $[34,35]$. Thus, if uterine ischemia is suspected, application of compression suture removal [36] or other contrivance [37] may help avoid irreversible uterine necrosis. Ligation of the internal iliac artery is not likely to be successful because arterial anastomoses are abundant during pregnancy. Hybrid operating rooms and intraoperative use of interventional radiology allow achievement of hemostasis by employing arterial embolization or balloon occlusion
[38]. Arterial embolizations are associated with subsequent complications, such as pain and adhesion due to uterine ischemia, oligomenorrhea due to endometrial hypoplasia, and hypomenorrhea, and increased frequencies of infertility, preterm birth, fetal growth restriction, uterine rupture, and placenta accreta in subsequent pregnancies [38-46].

To treat bleeding in patients with DIC after vaginal delivery, intrauterine balloon tamponade should be attempted first, whereas invasive treatments, including arterial embolization and laparotomy, should be considered if balloon tamponade has failed $[20,47]$. Whatever the clinical circumstances, hemostasis is difficult to achieve if the blood fibrinogen level is less than $150 \mathrm{mg} / \mathrm{dL}$. Therefore, supplemental coagulation factors should be provided as promptly as possible, while performing pressure hemostasis.

\section{Damage control}

Regardless of whether massive bleeding occurs during cesarean section or after vaginal delivery, the bleeding cannot be stopped quickly unless DIC is controlled. In such cases, damage control surgery (DCS) [48] and resuscitation [49], the therapeutic strategies for severe trauma accompanied by major bleeding, should be performed. In the field of emergency medicine, DCS rather than routine surgical procedures is commonly performed for the treatment of severe trauma accompanied by hemorrhagic shock. This is because the main cause of intraoperative or postoperative death in patients with severe trauma accompanied by massive bleeding is not blood loss due to failure to control the bleeding source but, rather, collapse of physiological homeostasis characterized by the so-called lethal triad of death, i.e., lethal combination of hypothermia, metabolic acidosis, and coagulation disorder [50-52]. Therefore, while pressure hemostasis is performed using gauze or towel packing as part of DCS, the clinical situation should be fully ascertained, keeping warm, rapid blood transfusion and other measures should be made, and resuscitation should be performed to rescue the patient from shock or DIC. If bleeding is determined to be uncontrollable, the surgical wound should be closed with packing in place, and the patient should be transferred to a higher-level medical facility.

Bleeding may become uncontrollable due to DIC during cesarean section in cases with placental abruption. In such cases, pressure should be applied with a towel or a gauze first, and FFP, fibrinogen, or cryoprecipitate prepared in the 


\section{Obstetrics \& Gynecology Science}

Vol. 62, No. 5, 2019

facility should then be administered, rather than proceeding to hysterectomy. If the lethal triad of death is eliminated by these procedures, hysterectomy can be avoided. Because the situation may worsen during hysterectomy, pressure should be applied with a towel or a gauze after removing the uterus, and attention should be focused on the DIC treatment. When the bleeding tendency improves, laparotomy wound should be closed, with a drainage tube inserted. Performing resuscitation while surgical procedures are temporarily suspended allows us to avoid unnecessary hysterectomy and hemorrhagic death.

As a method similar to towel packing, Charoenkwan [53] reported a hemostatic technique employing a Bakri balloon for bleeding from the pelvic floor after hysterectomy. With this procedure, the posterior vaginal fornix is elevated with compression toward the Douglas' pouch for the treatment of bleeding from the pelvic floor after hysterectomy. Using it as a mark, the Douglas' pouch is incised transversely by $2.5 \mathrm{~cm}$ to achieve communication. The opposite side of the balloon is inserted into the site toward the area outside the vagina. Absorptive hemostatic material is attached to the bleeding site, and pressure is applied to the pelvic floor by infusing $400-500 \mathrm{~mL}$ of physiological saline in the balloon. After 24-30 hours of pressure hemostasis, the balloon is removed from the vagina. Charoenkwan [54] also reported a hemostatic technique employing a Bakri balloon to control bleeding from the posterior surface of the uterus.

\section{Measures to improve outcomes}

The Recurrence Prevention Committee of the Japan Obstetric Compensation System analyzed 176 cases of placental abruption and reported specific recommendations [14].

\section{Health guidance for pregnant women}

Because placental abruption is a condition that may lead to serious events in both the mother and neonate, pregnant women should accurately understand this pathological condition. It is difficult to differentiate the early symptoms of abdominal pain and genital bleeding from the signs of threatened preterm labor. Therefore, pregnant women should be instructed to quickly seek care at a medical institution if these symptoms occur. In particular, when risk factors such as hypertensive disorder of pregnancy, history of placen- tal abruption, and trauma are observed, guidance for selfmanagement of pregnant women and health check-ups with proper timing or at appropriate intervals for prevention and early detection should be provided. In addition, these women should be urged to stop smoking because tobacco use is associated with threatened premature labor and placental abruption and has a harmful influence on fetal growth [55].

Among the chief complaints of 123 placental abruption cases from outside obstetric facilities, abdominal pain was noted in $69.1 \%$, genital bleeding in $44.7 \%$, feeling of abdominal tension in $43.1 \%$, and changes in fetal movement (reduction or absence of movement, intense movement) in $22.0 \%$ of patients [14]. Early consultation with a medical institution, without hesitation or delay, should be fully explained to all pregnant women and their families [14]. Health guidance should be provided, keeping the aforementioned symptoms in mind, particularly when the following risk factors are present: pregnancy-induced hypertension, history of placental abruption, trauma (traffic accident, abdominal contusion, etc.), maternal age of $\geq 35$ years, smoking status, pregnancy through in vitro fertilization and embryo transfer, and chronic hypertension [14].

\section{Differentiation from preterm labor}

Symptoms of placental abruption at onset are difficult to differentiate from those of threatened preterm labor. Therefore, in patients with signs of threatened preterm labor, differential diagnosis is necessary, keeping placental abruption in mind, using fetal heart rate monitoring, close examination by ultrasonography of the fetus and the placenta (posterior hematoma, thickening and enlargement of the placenta), and detailed blood examinations (blood counts, biochemistry, blood coagulation, and fibrinolytic assay) [14]. Administration of tocolytic agents without obtaining an accurate differential diagnosis must be avoided. In the advanced stage, placental separation is accompanied by tenderness, and the uterus shows prolonged contraction in the form of a rigid boardlike abdomen, indicating an elevated fundus of the uterus.

\section{Diagnosis}

When women with abnormal signs during pregnancy are examined or when any pregnant woman is admitted for delivery, the fetal health should be confirmed using a cardiotocogram for a certain period of time (at least 20 minutes). Late deceleration, severe variable deceleration, or ripple-like 


\section{Obstetrics \& Gynecology Science}

Jun Takeda, et al. Management of DIC with abruption

uterine contractions may be observed. The paper feeding velocity of the cardiotocogram should be $3 \mathrm{~cm} / \mathrm{min}$. When the velocity is 1 or $2 \mathrm{~cm} / \mathrm{min}$, early, late, and variable decelerations cannot be differentiated in order to assess baseline variability. It is important that all obstetric health professionals attend training programs in their respective facilities to enhance their ability to read cardiotocograms. A diagnosis should be made, considering not only the aforementioned representative signs of threatened preterm labor but also signs of labor onset such as the onset of labor pain and sensation that membrane rupture has occurred as well as the rare symptoms of dizziness and defecation urgency [14].

\section{Management after diagnosis}

When placental abruption is diagnosed, the method of forced delivery, request for pediatric support, and need for transport of the mother and neonate should be determined, taking maternal management for DIC and fetal management for preterm birth into account, and the fetus should be delivered as soon as possible. If neonatal asphyxia is recognized, resuscitation should be performed immediately according to the guideline of Neonatal Cardiopulmonary Resuscitation (NCPR). When NCPR is performed, neonatal management should be considered including indications for hypothermic therapy [14].

Even if prompt documentation in the form of a medical record is not possible in an acute situation, a brief note should be provided immediately, and details should be described in the medical record when emergency treatment has been completed. The following should be documented in the medical record: complaints of pregnant and parturient women, internal and external examination findings, ultrasound tomography findings, cardiotocography findings, blood examination results, subsequent treatment, mode of delivery, forced delivery, surgical findings, and circumstances of and management provided during maternal transport [14].

\section{Development of the emergency care system}

Practical guidelines that specify the response of personnel to pregnant women who complained of symptoms suggestive of serious conditions such as placental abruption (genital bleeding, abdominal pain, sensation of abdominal tension, and decreased fetal movement, among others), subsequent prompt reporting to obstetricians and midwives and their responses should be established in their respective facili- ties to initiate proper management [14]. Procedures such as emergency summoning of staff, preparation for emergency surgery, and how to determine the degree of urgency and proper notification thereof should be discussed in advance. In each facility, provision of manpower in emergency situations, responses (including blood transfusion) to bleeding in pregnant women, resuscitation of neonates, and neonatal management including hypothermic therapy should be considered, and institutional guidelines for forced delivery, request for maternal transport, request for pediatric support during delivery, and request for neonatal transport should be established [14].

Responses to maternal emergencies including placental abruption and obstetric critical bleeding associated with serious events for the mother and neonate should be simulated on a routine basis through maternal emergency training programs provided by the Japan Council for Implementation of Maternal Emergency Life Saving System (J-CIMELS) $[56,57]$ or other organizations.

When accepting pregnant women with known or suspected placental abruption, preparations for forced delivery and neonatal resuscitation should be made before their arrival. When such pregnant women arrive, fetal status and placental separation should be assessed immediately to determine the optimal treatment strategy [14].

\section{Development of the transport system}

To improve the outcomes of both the mother and neonate in placental abruption cases, further strengthening of relevant systems including development and improvement of higher-level medical facilities, enhancement of maternal and neonatal transport systems, and establishment of a transport system serving a large area in each region are important [14].

\section{Conclusion}

Placental abruption with DIC should be managed in collaboration with not only obstetricians but also systemic management physicians (anesthesiologists, emergency physicians, etc.), inspection department, blood transfusion department, department of radiology, nursing department, and so on. Early diagnosis and treatment are desired to reduce mortality due to obstetrical critical hemorrhage. 


\section{Obstetrics \& Gynecology Science}

Vol. 62, No. 5, 2019

\section{Conflict of Interest}

No potential conflict of interest relevant to this article was reported.

\section{References}

1. Baumann P, Blackwell SC, Schild C, Berry SM, Friedrich $\mathrm{HJ}$. Mathematic modeling to predict abruptio placentae. Am J Obstet Gynecol 2000;183:815-22.

2. Kyrklund-Blomberg NB, Gennser G, Cnattingius S. Placental abruption and perinatal death. Paediatr Perinat Epidemiol 2001;15:290-7.

3. Ananth CV, Wilcox AJ. Placental abruption and perinatal mortality in the United States. Am J Epidemiol 2001;153:332-7.

4. Tikkanen M, Nuutila M, Hiilesmaa V, Paavonen J, Ylikorkala O. Prepregnancy risk factors for placental abruption. Acta Obstet Gynecol Scand 2006;85:40-4.

5. Ananth CV, Cnattingius S. Influence of maternal smoking on placental abruption in successive pregnancies: a population-based prospective cohort study in Sweden. Am J Epidemiol 2007;166:289-95.

6. Nilsen RM, Vollset SE, Rasmussen SA, Ueland PM, Daltveit AK. Folic acid and multivitamin supplement use and risk of placental abruption: a population-based registry study. Am J Epidemiol 2008;167:867-74.

7. Tikkanen M. Placental abruption: epidemiology, risk factors and consequences. Acta Obstet Gynecol Scand 2011;90:140-9.

8. Tikkanen M, Nuutila M, Hiilesmaa V, Paavonen J, Ylikorkala O. Clinical presentation and risk factors of placental abruption. Acta Obstet Gynecol Scand 2006;85:700-5.

9. Bodelon C, Bernabe-Ortiz A, Schiff MA, Reed SD. Factors associated with peripartum hysterectomy. Obstet Gynecol 2009;114:115-23.

10. Tikkanen M, Gissler M, Metsäranta M, Luukkaala T, Hiilesmaa $V$, Andersson $S$, et al. Maternal deaths in Finland: focus on placental abruption. Acta Obstet Gynecol Scand 2009;88:1124-7.

11. Ananth CV, Berkowitz GS, Savitz DA, Lapinski RH. Placental abruption and adverse perinatal outcomes. JAMA 1999;282:1646-51.

12. Iwashita M. No fault compensation in perinatal medicine in Japan-from results for 8 years. Obstet Gynecol Sci 2017;60:139-44.

13. Hasegawa J, Toyokawa S, Ikenoue T, Asano Y, Satoh S, Ikeda $T$, et al. Relevant obstetric factors for cerebral palsy: from the nationwide obstetric compensation system in Japan. PLoS One 2016;11:e0148122.

14. Japan Council for Quality Health Care. The Japan obstetric compensation system for cerebral palsy. In the 6th recurrence prevention report. in Japanese [Internet]. Tokyo: Japan Council for Quality Health Care; 2016 Mar [cited 2018 Dec 21]. Available from: http://www. sanka-hp.jcqhc.or.jp/documents/prevention/report/pdf/ Saihatsu_Report_06_All.pdf.

15. Ananth CV, Peltier MR, Kinzler WL, Smulian JC, Vintzileos AM. Chronic hypertension and risk of placental abruption: is the association modified by ischemic placental disease? Am J Obstet Gynecol 2007;197:273.e17.

16. Ruiter L, Ravelli AC, de Graaf IM, Mol BW, Pajkrt E. Incidence and recurrence rate of placental abruption: a longitudinal linked national cohort study in the Netherlands. Am J Obstet Gynecol 2015;213:573.e1-8.

17. Matsuda Y, Kawamichi Y, Hayashi K, Shiozaki A, Satoh S, Saito $S$. Impact of maternal age on the incidence of obstetrical complications in Japan. J Obstet Gynaecol Res 2011;37:1409-14.

18. Oyelese Y, Ananth CV. Placental abruption. Obstet Gynecol 2006;108:1005-16.

19. Page EW, King EB, Merrill JA. Abruptio placentae; dangers of delay in delivery. Obstet Gynecol 1954;3:385-93.

20. Takeda S, Makino S, Takeda J, Kanayama N, Kubo T, Nakai A, et al. Japanese clinical practice guide for critical obstetrical hemorrhage (2017 revision). J Obstet Gynaecol Res 2017;43:1517-21.

21. American College of Surgeons. ACS TQIP massive transfusion in trauma guidelines [Internet]. Chicago (IL): American College of Surgeons; [cited 2018 Dec 21]. Available from: https://www.facs.org/-/media/files/ quality-programs/trauma/tqip/transfusion_guildelines. ashx?la=en.

22. Matsunaga S, Seki $H$, Ono $Y$, Matsumura $H$, Murayama $Y$, Takai $Y$, et al. A retrospective analysis of transfusion management for obstetric hemorrhage in a Japanese obstetric center. ISRN Obstet Gynecol 2012;2012:854064.

23. Association of Anaesthetists of Great Britain and Ireland, 


\section{Obstetrics \& Gynecology Science}

Jun Takeda, et al. Management of DIC with abruption

Thomas D, Wee M, Clyburn P, Walker I, Brohi K, et al. Blood transfusion and the anaesthetist: management of massive haemorrhage. Anaesthesia 2010;65:1153-61.

24. Prevention and management of postpartum haemorrhage: Green-top Guideline No. 52. BJOG 2016;124:e106-49.

25. Makino S, Takeda S, Kobayashi T, Murakami M, Kubo T, Hata $T$, et al. National survey of fibrinogen concentrate usage for post-partum hemorrhage in Japan: investigated by the Perinatology Committee, Japan Society of Obstetrics and Gynecology. J Obstet Gynaecol Res 2015;41:1155-60.

26. Matsunaga S, Takai Y, Nakamura E, Era S, Ono Y, Yamamoto $K$, et al. The clinical efficacy of fibrinogen concentrate in massive obstetric haemorrhage with hypofibrinogenaemia. Sci Rep 2017;7:46749.

27. Kikuchi M, Itakura A, Miki A, Nishibayashi M, Ikebuchi K, Ishihara O. Fibrinogen concentrate substitution therapy for obstetric hemorrhage complicated by coagulopathy. J Obstet Gynaecol Res 2013;39:770-6.

28. Mallaiah S, Barclay P, Harrod I, Chevannes C, Bhalla A. Introduction of an algorithm for ROTEM-guided fibrinogen concentrate administration in major obstetric haemorrhage. Anaesthesia 2015;70:166-75.

29. Murakami M, Kobayashi T, Kubo T, Hata T, Takeda S, Masuzaki $H$. Experience with recombinant activated factor VII for severe post-partum hemorrhage in Japan, investigated by Perinatology Committee, Japan Society of Obstetrics and Gynecology. J Obstet Gynaecol Res 2015;41:1161-8.

30. B-Lynch C, Coker A, Lawal AH, Abu J, Cowen MJ. The BLynch surgical technique for the control of massive postpartum haemorrhage: an alternative to hysterectomy? Five cases reported. Br J Obstet Gynaecol 1997;104:3725.

31. Hayman RG, Arulkumaran S, Steer PJ. Uterine compression sutures: surgical management of postpartum hemorrhage. Obstet Gynecol 2002;99:502-6.

32. Makino S, Hirai C, Takeda J, Yorifuji T, Itakura A, Takeda $S$. Hemostatic technique during cesarean section. Hypertens Res Pregnancy 2016;4:6-10.

33. Makino S, Tanaka T, Yorifuji T, Koshiishi T, Sugimura M, Takeda S. Double vertical compression sutures: a novel conservative approach to managing post-partum haemorrhage due to placenta praevia and atonic bleeding.
Aust N Z J Obstet Gynaecol 2012;52:290-2.

34. Poujade O, Grossetti A, Mougel L, Ceccaldi PF, Ducarme $G$, Luton D. Risk of synechiae following uterine compression sutures in the management of major postpartum haemorrhage. BJOG 2011;118:433-9.

35. Gottlieb AG, Pandipati S, Davis KM, Gibbs RS. Uterine necrosis: a complication of uterine compression sutures. Obstet Gynecol 2008;112:429-31.

36. Takeda J, Kumakiri J, Makino S, Itakura A, Takeda S. Laparoscopic removal of uterine vertical compression sutures. Gynecol Minim Invasive Ther 2017;6:73-5.

37. Takeda J, Makino S, Matsumura Y, Itakura A, Takeda S. Enclosing sutures technique for control of local bleeding in a case of placenta increta. J Obstet Gynaecol Res 2018;44:1472-5.

38. Sone M, Nakajima Y, Woodhams R, Shioyama Y, Tsurusaki $M$, Hiraki T, et al. Interventional radiology for critical hemorrhage in obstetrics: Japanese Society of Interventional Radiology (JSIR) procedural guidelines. Jpn J Radiol 2015;33:233-40.

39. Takeda J, Makino S, Ota A, Tawada T, Mitsuhashi N, Takeda S. Spontaneous uterine rupture at 32 weeks of gestation after previous uterine artery embolization. J Obstet Gynaecol Res 2014;40:243-6.

40. Sano Y, Takeda J, Kuroda K, Makino S, Itakura A, Takeda $\mathrm{S}$. Embrittlement of uterus after uterine artery embolization: a case of uterine perforation. Hypertens Res Pregnancy 2016;4:42-4.

41. Inoue S, Masuyama H, Hiramatsu Y; Multi-Institutional Study Group of Transarterial Embolization for Massive Obstetric Haemorrhage in Chugoku \& Shikoku Area Society of Obstetrics and Gynecology. Efficacy of transarterial embolisation in the management of post-partum haemorrhage and its impact on subsequent pregnancies. Aust N Z J Obstet Gynaecol 2014;54:541-5.

42. Bradley LD. Uterine fibroid embolization: a viable alternative to hysterectomy. Am J Obstet Gynecol 2009;201:127-35.

43. Maassen MS, Lambers MD, Tutein Nolthenius RP, van der Valk PH, Elgersma OE. Complications and failure of uterine artery embolisation for intractable postpartum haemorrhage. BJOG 2009;116:55-61.

44. Mara M, Maskova J, Fucikova Z, Kuzel D, Belsan T, Sosna $O$. Midterm clinical and first reproductive results of a randomized controlled trial comparing uterine fibroid 


\section{Obstetrics \& Gynecology Science}

Vol. 62, No. 5, 2019

embolization and myomectomy. Cardiovasc Intervent Radiol 2008;31:73-85.

45. Goldberg J, Pereira L, Berghella V, Diamond J, Daraï E, Seinera $P$, et al. Pregnancy outcomes after treatment for fibromyomata: uterine artery embolization versus laparoscopic myomectomy. Am J Obstet Gynecol 2004;191:18-21.

46. Shashoua AR, Stringer NH, Pearlman JB, Behmaram B, Stringer EA. Ischemic uterine rupture and hysterectomy 3 months after uterine artery embolization. J Am Assoc Gynecol Laparosc 2002;9:217-20.

47. Makino S, Takeda J, Hirai C, Itakura A, Takeda S. Uterine balloon tamponade as a test to assess further treatment. Acta Obstet Gynecol Scand 2015;94:556.

48. Weber DG, Bendinelli C, Balogh ZJ. Damage control surgery for abdominal emergencies. $\mathrm{Br}$ J Surg 2014;101:e109-18.

49. Lamb CM, MacGoey P, Navarro AP, Brooks AJ. Damage control surgery in the era of damage control resuscitation. Br J Anaesth 2014;113:242-9.

50. Wyrzykowski A. Trauma damage control. In: Trauma. 7th ed." Mattox KL, Moore EE, Feliciano DV, editors. New York (NY): McGraw-Hill; 2013. p.725-46.

51. Moore EE, Burch JM, Franciose RJ, Offner PJ, Biffl WL. Staged physiologic restoration and damage control surgery. World J Surg 1998;22:1184-90.

52. Shapiro MB, Jenkins DH, Schwab CW, Rotondo
MF. Damage control: collective review. J Trauma 2000;49:969-78.

53. Charoenkwan K. Effective use of the Bakri postpartum balloon for posthysterectomy pelvic floor hemorrhage. Am J Obstet Gynecol 2014;210:586.e1-3.

54. Charoenkwan K. Use of the Bakri postpartum balloon in a patient with intractable pelvic floor hemorrhage: when other methods failed to stop postcesarean bleeding, physicians tried something new. Am J Obstet Gynecol 2013;209:277.e1-5.

55. Japan Council for Quality Health Care. The Japan obstetric compensation system for cerebral palsy. In the 2nd recurrence prevention report. in Japanese [Internet]. Tokyo: Japan Council for Quality Health Care; 2012 May [cited 2018 Dec 21]. Available from: http://www. sanka-hp.jcqhc.or.jp/documents/prevention/report/pdf/ Saihatsu_Report_02_All.pdf.

56. Japan Council for Implementation of Maternal Emergency Life-Saving System (J-CIMELS). J-CIMELS website [Internet]. Tokyo: Japan Council for Implementation of Maternal Emergency Life-Saving System; [cited 2018 Dec 21]. Available from: https://www.j-cimels.jp/index. html.

57. Takeda S. Education and training approach aimed at reducing the maternal deaths in Japan. Hypertens Res Pregnancy 2018;6:15-9. 